\title{
Correction to: Factors affecting reproductive performance in dromedary camel herds in Saudi Arabia
}

\author{
Ahmed Ali $^{1,2} \cdot$ Derar Derar $^{1,2} \cdot$ Abdulhadi Alsharari $^{1} \cdot$ Assaf Alsharari $^{1} \cdot$ Rashid Khalil $^{1} \cdot$ Tariq I. Almundarij $^{1}$. \\ Yaser Alboti ${ }^{1} \cdot$ Fahd Al-Sobayil $^{1}$
}

Published online: 10 July 2019

(C) Springer Nature B.V. 2019

Correction to: Tropical Animal Health and Production (2018) 50:1155-1160

https://doi.org/10.1007/s11250-018-1545-3

This article was originally published with incorrect affiliation 1 . The correction affiliation is presented below.

Publisher's note Springer Nature remains neutral with regard to jurisdictional claims in published maps and institutional affiliations.

The online version of the original article can be found at https://doi.org/ 10.1007/s11250-018-1545-3

Ahmed Ali

drahmedali77@gmail.com

1 Department of Veterinary Medicine, College of Agriculture and Veterinary Medicine, Qassim University, P.O. Box 6622,

Buraidah 51452, Saudi Arabia

2 Department of Theriogenology, Faculty of Veterinary Medicine, Assiut University, Assiut 71526, Egypt 